Eichler on the reorientation effect in Coulomb excitation. The articles are clearly written, particularly those by Ripka and Duck, but the level rarely rises above competence and it seems doubtful whether these articles will excite enthusiasm in any reader not already familiar with the subject.

The whole volume has a rather dull appearance by the standards normally associated with American publishers. There are a few misprints, and a lack of uniformity of references and symbols. This lack of uniformity is not a serious matter to those accustomed to read a wide range of journals, but for the sake of research students it must be hoped that the editors will impose a standard notation for such basic quantities as Clebsch-Gordan coefficients and spherical harmonics. The figures are particularly disappointing, and in so expensive a volume something better can reasonably be expected.

The present volume does not live up to the stated intentions of the editors, but it has sufficient merit that one may hope the series will continue and succeed.

DAPHNE F. JACKSON

\section{BUBBLES AND SPARKS}

\section{Bubble and Spark Chambers}

Principles and Use. Vol. 1. Edited by R. P. Shutt. (Pure and Applied Physics: a Series of Monographs and Textbooks, Vol. 27-1.) Pp. $x+425$. (New York: Academic Press, Inc.; London: Academic Press, Inc. (London), Ltd, 1967.) 172s.

THus book consists of six chapters, all written by people who are still active in their respective fields of research. The emphasis throughout is on the basic principles of operation and the bibliographical approach is, mercifully, avoided.

Chapter 1, by Thorndike, is a short but very useful introduction to the subject and would be particularly useful to the reader studying bubble and spark chamber techniques for the first time. The next chapter, on "Bubble Chamber Principles", is by Peyrou, where he reviews our basic knowledge of the theory of bubble formation. This is an excellent account of a subject that is still in an unsatisfactory state theoretically.

The third chapter is a long one on "Cryogenic Bubble Chambers" by W. B. Fowler. It contains a wealth of important information on the design and operation of low-temperature bubble chambers. The design criteria are clearly given and the various ways of meeting the design requirements are explained. This is a complicated business involving a great deal of engineering and team work. It is well worth reading. Lagarrigue and Rousset contribute an article on "Heavy Liquid Bubble Chambers". The advantages and disadvantages of using liquids with high density and atomic number are explained by quoting actual experiments. Constructional techniques are demonstrated by explaining the principle of construction of several large heavy liquid chambers. The special problems in data handling as a result of using "heavy" fillings are thoroughly explained and the special tech. niques which can be used at the scanning stage to identify tracks and events are given in sufficient detail to give the reader a feeling of involvement. The chapter ends with a description of several experiments to demonstrate the particular qualities of heavy liquids.

Chapter 5 is written by Welford and is a thoroughly competent and balanced account of some of the design and constructional problems in the illumination and photography of bubble chambers. The author has wisely avoided describing in any detail systems which have not yet been tried.

The last chapter, by James W. Cronin, is devoted to spark chambers and gives a very useful account of the basic theorie of operation, the problems of dead time and methods of clearing. Constructional techniques for both small spark chambers and the very large ones are explained. Triggering arrangements in use with spark chambers are carefully shown and the principles of photography are given. The factors affecting the accuracy of the location of the trajectory from spark positions are described. The chapter contains a very good account of some applications of the spark chamber technique. Reference is made at the end to the development of wide-gap, projection and streamer chambers. The emphasis in the chapter is on explaining established techniques without too much speculation. This leads to a most informative and well-balanced account.

My general impression is that this volume is very well produced with good clear drawings and photographs. It is excellent reading for anyone who is genuinely interested in bubble and spark chambers.

W. H. Evans

\section{FUNGICIDES}

\section{Fungicides}

An Advanced Treatise. Edited by Dewayne C. Torgeson. Vol. 1: Agricultural and Industrial Applications, Environmental Interactions. Pp. $\mathrm{xv}+697$. (Now York: Academic Press, Inc. ; London : Academic Press, Inc. (London), Ltd, 1967.) $270 s$.

THIs, the first of a two-volume treatise, is mainly concerned with the development and use of fungicides. The second volume, now in preparation, will deal with the various types of fungicides, and how they affect bacteria and fungi.

The treatise begins with an historial survey of the use of fungicides, a general account of present usage, and a discussion about possible developments. These topics are followed by analyses of the effects of fungicides on the early stages of infection of plants by pathogens, and on the development of epidemics in crops.

Identification of new fungicides, formulation and development into commercial products are described fully in three chapters. Four chapters deal more specifically with the use of fungicides in soil and to treat seeds, against shoot and foliage pathogens and in the control of postharvest diseases. There are also full accounts of the physical and chemical factors that affect deposition and behaviour of fungicides on plants, how fungicides get into and move through plants, and how they are altered by micro-organisms and higher plants. The book is concluded by two chapters, again comprehensive in their treatment, on the preservation of wood and many other manufactured products with fungicides.

The fifteen chapters are written by internationally recognized experts in their fields. Each is self-contained and authoritative, and ends with a comprehensive list of references. In a treatise of this kind, it is, of course, difficult to avoid some duplication of treatment in successive chapters, but the editor and authors are to be congratulated on their success in reducing this to a minimum.

An attractive feature of the book is the way in which it combines theoretical and practical considerations, ranging as it does from the physical chemistry of fungicides deposited on plant surfaces and the biochemistry of the degradation of fungicides by micro-organisms, to the practical aspects of applying fungicides to soil and the financial implications of developing fungicides on a commercial scale. It would be difficult to think of any aspect that has not been dealt with in detail, bearing in mind what is promised in the second volume. A possible exception is the development of resistance to fungicides and why this has not so far become a practical problem as it has for insecticides and antibiotics.

Publication of this treatise is to be regarded as a major event in plant pathology, and possession or access to it will be obligatory for all who work with fungicides, and to 